Caligrama, Belo Horizonte, v.19, n.2, p. 99-130, 2014

\title{
Cadê e variantes: gramaticalização em língua portuguesa
}

\section{Cadê and variants: grammaticalization in Portuguese}

Odete Pereira da Silva Menon

Universidade Federal do Paraná / Conselho Nacional de Desenvolvimento Científico e Tecnológico, Curitiba, Paraná, Brasil

odete@ufpr.br

Resumo: A gramaticalização da frase "Que é feito de fulano?", passando por "Que é de fulano?" resultou em "Que é de?", seguida da contração entre a vogal do pronome e o verbo (queé> qué) "Qu'é de?"> "Quede?", forma contracta empregada por Sá de Miranda, nascido em 1481 (trata-se, portanto, de forma já em uso na segunda metade do século XV) . Depois, esse quede adquire acento na última sílaba, provavelmente devido ao fato de ocorrer isolado, em fim de frase, na repetição enfática, onde recebe acento frasal (de intensidade três, contra a intensidade um, de vocábulo): "Quede o chapéu? Quedê?". Por meio da retomada anafórica "Que é feito dele?", reduzida para "Que é dele?", resulta outra variante: quedele. Aparentemente, a variante cadê tem tido um uso mais corrente no Brasil, o que leva muita gente a afirmar que se trata de um brasileirismo. No entanto, as outras variantes - quede / quedê ou quedele / cadele - são empregadas em diferentes partes do país e algumas delas podem ser encontradas em textos do português europeu de diferentes épocas.

Palavras-chave: cadê e variantes; gramaticalização, variação e mudança; história do português.

Abstract: The grammaticalization of the sentence "Que é feito de fulano?" became "Que é de fulano?" "What about so-and-so?" "Where is so-andso?") and resulted in "Que é de?", followed by the contraction of the pronoun's vowel and the verb (que é> qué) "Qu'é de?"> "Quede?", a 
contracted form used by Sá de Miranda, born in 1481 (it is, thus, a form currently used in the second half of the $15^{\text {th }}$ century). Then, quede starts to be stressed in its last syllable, probably due to this being alone at the end of a sentence, in an emphatic repetition context, where it receives phrasal stress - whose intensity (3) is higher than that of a phonological word (1): “Quede o chapéu? Quedê?”. By the anaphora “Que é feito dele?" reduced to "Que é dele?", which resulted in another variant: quedele. Apparently, the variant cadê has been more widely used in Brazil, what takes many people to claim it is a "brasileirismo" (a typical feature of Brazilian Portuguese). Nevertheless, the other variants - quede / quedê or quedele / cadele - are used in different parts of the country and some of them may also be found in European Portuguese texts of different centuries.

Keywords: cadê and variants; grammaticalization; variation and change; history of Portuguese language.

Recebido em 30 de novembro de 2014. Aprovado em 17 de dezembro de 2014.

\section{Introdução}

Este estudo teve origem num convite para discutir fenômenos de morfologia em uma mesa-redonda, no III Congresso Internacional de Dialetologia e Sociololinguística (MENON, 2014). Pretendia (i) abordar as variantes cadê / quedê / quede / quedele do ponto de vista sincrônico, para verificar distribuição regional, visto que são consideradas nos dicionários e em outras fontes, inclusive na internet, como exclusivas do português do Brasil; (ii) apresentar a sua origem, demonstrando que ela remonta à língua usada em Portugal em período anterior ao da descoberta do Brasil. Porém, à medida que a pesquisa foi avançando no preparo da apresentação, novos dados e informações bibliográficas foram se agregando a esse conteúdo, que se restringiria originalmente a abordar o pronome/advérbio interrogativo cadê / quedê como resultado de lexicalização, via gramaticalização, da frase "Que é feito de [fulano]?"

O resultado dessa indagação, - que não se quer exaustivo, nem definitivo -, revelou não um, mas vários processos, ou etapas diferenciadas, de gramaticalização e variação. Num primeiro momento, há um processo de competição entre uma forma nova de perguntar a respeito de alguém (“Como está? Por onde anda?"): “Que é feito de 
fulano?" que concorre/coocorre com uma forma existente, "Ulo fulano?" (composta do advérbio $u<$ lat. $u b i$, "onde", mais o artigo arcaico lo; também possível no feminino). Temos aí um caso típico de variação e mudança, com o desaparecimento da forma mais antiga, talvez devido ao fato de que o advérbio $u$ deixou de ser empregado em português, em proveito de onde (< lat. unde, "de onde"). Entretanto, essa fase do processo de variação e mudança, que redundou no desaparecimento de ulo não vai ser conduzida de modo sistemático neste estudo, visto ter sido uma descoberta no meio do caminho e exigir, para efeitos de comprovação de período e intensidade de uso, levantamento de obras da metade do século XV para trás. Ora, todos os que trabalham com história da língua portuguesa, sobretudo do teatro, sabem que não se conservou praticamente nada dos textos anteriores a Gil Vicente e, mesmo na prosa ou em verso, há muito pouco texto dialogado preservado. Basta uma consulta aos catálogos da Biblioteca Nacional de Portugal ou da Fundação Calouste Gulbenkian, com entrada em teatro ou entremeses, para se comprovar essa afirmação. Exigiria, igualmente, busca em textos até o século XVII, visto que Said Ali (1964, p. 185) consigna ainda um exemplo de uso de variante de ulo (adulo) em Dom Francisco Manuel de Mello (conforme adiante na seção 3.1), embora tal uso possa ser meramente residual, de sobrevivência da forma arcaizada. Por isso, as referências a esse processo vão permear a exposição do desenvolvimento das etapas de gramaticalização de "Que é feito de fulano?".

Uma vez fixada no uso a forma vencedora, com o tempo e em decorrência da intensidade do seu emprego ${ }^{1}$ se inicia um processo de gramaticalização da forma que é de > quede, com desenvolvimento de variantes fonológicas (cadê, quedê) e outro, da forma com retomada anafórica que é dele > quedele, também com desenvolvimento de variante: cadele.

Um terceiro momento, sequer vislumbrado no início do estudo, diz respeito ao processo de gramaticalização de cadê como marcador discursivo (MD): cadê que usado em contextos específicos e mais limitado, do ponto de vista gramatical, visto somente poder ocorrer em início de período, pois apresenta considerações, como uma pergunta retórica ("Quem disse que ...? Você pensa que ...? Imagine se ..."): "Cadê que ela estudou pra prova? Foi é pra balada!". Essa última etapa pertence, ao que parece e como indicam os dados, ao português do Brasil.

\footnotetext{
${ }^{1}$ Sobre a importância da frequência de uso das novas formas gramaticalizadas, veja-se o estudo de Lichtenberk (1991, em especial p. 51-56).
} 
Assim, este estudo vai abordar esse fenômeno não como um único processo, desenvolvido de maneira linear, mas sim de múltiplos processos de gramaticalização, em diferentes etapas e com diferentes resultados, no português do Brasil (PB) e no de Portugal (PE). Para tanto, consideramos gramaticalização conforme vem sendo tratado e aperfeiçoado, a partir da formulação original de Meillet (1912): um processo histórico ${ }^{2}$ de transformação de unidades linguísticas autônomas em unidades (mais) condicionadas gramaticalmente. Às noções dos estudos já tradicionais como os de Kurylowicz (1975, p. 50-53), Heine et al. (1991), Lichtenberk (1991), Hopper e Traugott (1993), entre outros, sobre as etapas e os processos de gramaticalização das formas, acrescentaram-se as de Diewald (2008) e Diewald e Smirnova (2012) sobre a integração das formas gramaticalizadas em novos paradigmas (cadêlquedê e cadele/quedele, novos pronomes/advérbios interrogativos; cadê que: novo marcador discursivo, introdutor de considerações).

Por se tratar de unidades linguísticas (frase completa "Que é feito de fulano?", depois frase abreviada "Que é dele?"; e, em seguida, formas contractas "Qu'é dele?"> "Qu'é de?"> "Quede?") usadas para perguntas sobre algo ou alguém, a amostra histórica inicial (sécs. XVXVI) constituiu-se de consulta a textos dialogados (contexto no qual as formas devem se manifestar), em geral peças de teatro: textos de Sá de Miranda (1481-1558 3 ), Bernardim Ribeiro (1482?-1552?), Antonio Prestes (séc. XVI), Camões (1524?-1580), Jorge Ferreira de Vasconcelos (1515?-ca.1563-1585). Para o período entre o séc. XVII e o XXI, foi feita consulta a um corpus informatizado de língua portuguesa, o chamado Corpus Davies ${ }^{4}$, que revelou já existir a etapa de gramaticalização que conduziu ao marcador discursivo cadê que.

\footnotetext{
${ }^{2}$ Entretanto, o processo também poderia ser abordado sincronicamente, como ressalvaram Heine et al. (1991, p. 149): "What is common to all definitions of grammaticalization is, first, that it is conceived as a process. Although this process can be interpreted synchronically as well (cf. Li, 1975a; Lehmann, 1982, 2; Heine and Claudi, 1986) there is wide agreement that it forms essentially a diachronic phenomenon."

${ }^{3}$ As datas entre parênteses se referem ao nascimento e morte de cada autor, a partir dos registros contidos no Dicionário cronológico de autores portugueses (1985). A menção às datas é importante, visto que muitos autores foram publicados só tardia ou postumamente ou, ainda, há obras que permaneceram inéditas ou tiveram edições só muito recentemente. ${ }^{4}$ Disponível em: <www.corpusdoportugues.org $>$.
} 


\section{A origem, no PE}

Sob uma abordagem histórica, é possível analisar o processo de gramaticalização por que passou a frase "Que é dele?" (que constituiria retomada anafórica de "Que é (feito) ${ }^{5}$ de fulano?") até chegar a pronome interrogativo, com modificações fonéticas, entre as quais a contração da vogal do pronome que e a forma verbal é: [ke.'є] $>$ ['ke]. Essa sinalefa por elisão já se encontra registrada em verso ${ }^{6}$ em Sá de Miranda, nascido em 1481: " $Q$ 'é de mi, se não sou lá/ e cá comigo não vou?’'(SÁ DE MIRANDA, 1960, p. 5).

Mas parece ser anterior ao início do séc. XVI a elisão da vogal de que com a vogal constitutiva da forma verbal de terceira pessoa do singular do verbo ser é, pois aparece tanto em verso como em prosa, em diferentes autores, v.g. na obra Menina e Moça, de Bernardim Ribeiro, nascido cerca de 14827: "Qu'é isto, senhor Cavaleiro? the começou a dizer. Esforçai!" (PALMA-FERREIRA, 1982, p. 86). E Antônio Prestes (séc. XVI), no auto dos Dous hirmaos, utiliza simplesmente a abreviatura $\tilde{q}$ (usada para todos os tipos de que: conjunções, pronomes), para representar tal contração:

(1) $c i$. não vẽ meu pai, cõ. vẽ, $c i$. $\tilde{\mathbf{q}}$ dele ${ }^{8} / c \tilde{o}$. eylo ca efta dando o efprito / vamos velo (Autos, f. 83v).

O emprego da abreviatura nos faz crer que, então, já havia uma pronúncia [ke] ao lado de [ke], resultado normal da contração; temos,

\footnotetext{
${ }^{5}$ É muito raro encontrar a forma plena “Que é feito de [fulano]?"; nas obras consultadas só achei o exemplo (20): E delle que he feito? e, ainda, em ordem inversa. Isso pode ser um viés resultante da pequena amostra aqui empregada; talvez, com um número maior de obras, essa forma plena possa ser flagrada em número maior de ocorrências.. ${ }^{6}$ Nas citações de textos de poesia, a barra simples / é usada para separar os versos. Chamo a atenção para o fato de que nesta e em todas as outras abonações e citações, reproduzo rigorosamente a grafia do original consultado. Esse procedimento se estende também à apresentação das obras nas referências bibliográficas.

${ }^{7}$ A limitação a essas datas diz respeito ao corpus por mim utilizado; por isso, é talvez possível retroceder a datação a período anterior ao da segunda metade do séc. XV, o que não pôde ser feito para este trabalho. De todo modo, o fato de já aparecer na gramática de escritores nascidos na segunda metade dos quatrocentos atesta a antiguidade da forma e o fato de se ter originado em Portugal.

${ }^{8}$ Itálicos e negritos acrescentados; os itálicos são usados no registro das personagens que falam. Cabe observar que, nos textos dos autos, pode aparecer a fala de duas personagens dentro do mesmo verso, por razões de métrica e rima.
} 
portanto, um processo de variação com duas variantes do ponto de vista fonético: ['ke.de] e ['ke.de]. ${ }^{9}$

É verdade que se poderia argumentar ser a elisão devida a razões de métrica; porém, na outra vertente de variação, a partir de "Que é dele?" com a variante abreviada $\tilde{q}$ dele (= quedele), empregada por Prestes, também se encontra em texto em prosa, na Comédia Eufrosina: "Que'e delle?"10 (VASCONCELLOS, 1901, p. 221) do mesmo século.

Com base nessas abonações, de autores importantes do séc. XVI, constatamos a existência, no PE, de duas das variantes gramaticalizadas: quede (Sá de Miranda) e quedele (Prestes e Vasconcelos).

\section{Expressão só do PB?}

Uma repassada na internet, à procura de discussões sobre cadê, revelou um certo preconceito em relação à forma: "informal, do oral, de origem plebeia, nunca se deve escrever", preconceito esse que se contraria facilmente, quando se consulta um corpus de alguma envergadura, como o Corpus Davies, da Universidade de Georgetown, que reúne textos do $\mathrm{PB}$ e do PE, tanto escritos, como orais (esses mais recentes, da segunda metade do séc. XX para cá). Entretanto, a maior parte das pessoas que dão "receitas" de como se dizer ou escrever não é especialista em língua portuguesa e, entre os especialistas, há uma boa parcela que ignora as origens, a antiguidade, o desenvolvimento e a classificação morfológica da "expressão" cadê, como é por eles denominada, além de a circunscreverem ao território brasileiro, ainda que falem de outra variante, quede ou quedê.

\footnotetext{
${ }^{9} \mathrm{~A}$ transcrição fonética aqui empregada é lata: não se registra exatamente a variação que pode/possa ter existido na pronúncia do /e/ atóno final, por exemplo.

${ }^{10}$ Pode parecer estranho o fato de aparecer um apóstrofo entre que e a forma verbal, visto que o sinal indica que alguma coisa foi suprimida: e, realmente, foi, porque Jorge Ferreira de Vasconcellos emprega sempre a grafia he para a terceira pessoa do singular do verbo ser. Cabe lembrar que já se usou a letra $h$ em português, como recurso gráfico para indicar que há hiato e não ditongo; p. ex., em dahi, comprehender, ou em bahia (ba-hi-a), para diferenciar de baia (bai-a) "espaço delimitado por divisórias, em que ficam os cavalos, numa estrebaria". O apóstrofo indica que o hiato desapareceu, possibilitando o sândi e a leitura como uma única sílaba: [ke.'ع] $>$ ['kع], exatamente como em Sá de Miranda.
} 
No site acima citado, na busca por cadê, aparecem por último, nos dados do séc. XX, duas ocorrências em texto de jornal (data: 13.09.1996, título: Medo para que? [sic]), do PE, classificadas como do "brasilês", com avaliação depreciativa ${ }^{11}$ do PB:

Para já, vale a pena festejar o triunfo em Milão, algo que é muito raro (por isso inesquecível) e que os "tifosi" milaneses devem respeitar. Talvez um dia, na "Milan Point", a tal loja que vende o " merchandizing" do clube "rossoneri", o jornalista português encontre um vídeo deste AC Milao-F. C. Porto do dia 11 de Setembro de 1996.. \# np_jrn_726\#\# \# Em brasilês - idioma que se fala degenerado a partir do português no Brasil - há uma locução reduzida a palavra interrogativa "cadê", com origem na locução similar " que há dele " (indivíduo ou coisa), também usado por modismo deplorável no jornalismo popular português em Portugal por "jornalistas" ignorantes de gramaticalidade e linguística, em especial portuguesas! Pode haver variante a "cadê" por "càde" se a locução originadora for "que há de ele ou ela": cado; cada. Em Portugal, só se mudou ou já tinha sido mudado o verbo, ser (no caso português) por haver (...) ${ }^{12}$

Cadê é interpretado pelo autor da matéria como sendo derivada de "que há dele", com verbo haver ${ }^{13}$, para justificar a presença de $a$ ao invés de e: cadê por quedê (melhor seria de quede [ع] ou [ə], para o PE). Também ele dá mostras de ignorância, desconhecendo que em Portugal mesmo ocorre (i) um a pronunciado como chuá em sílaba átona, ato registrado em diferentes etapas da história da língua, e um e pronunciado como $\boldsymbol{a}$, como nestes excertos do Auto de Dom Fernando: "mas diz que me falará / da

\footnotetext{
${ }^{11}$ Como o site do corpus não fornece a referência bibliográfica completa da fonte, nem informa a página/seção onde se situam as ocorrências, não foi possível localizar em que jornal português teria sido publicado o trecho, para verificar qual a sequência da matéria, que se encerra, na abonação fornecida, na palavra [ (no ], tal qual aparece na citação. ${ }^{12}$ Disponível em: <www.corpusdoportugues.org> ; acesso em 31 out. 2014.

${ }^{13}$ Ainda não encontrei uma só abonação com verbo haver na frase que deu origem às formas gramaticalizadas deste trabalho. Também parecem bizarras as formas "cado, cada" mencionadas pelo autor daquele texto de jornal: na sua concepção, seriam contrações de $c a d \hat{e}+o$ e $c a d \hat{e}+a$ ?
} 
janela c'ũa escada"; "vou-me pôr a ũa jenela" e "Entre outras ũa cantiga / lhe fiz muito milagrosa / e ela todas asquiva" ("esquiva") (TEATRO, v. I, t. II, p. 108-109 e 128); e (ii) a pronúncia de um e tônico aberto (como no caso de quede) que se aproxima de um $a$, fato ainda vigente, como registrado por Florêncio (2005, p. 32), para o dialeto alentejano.

Também em Buescu (1984 [1958]), em sua monografia sobre etnografia e linguagem de Monsanto (com dados recolhidos antes de 1953), encontramos abonações que registram essa alternância e/a: govarnador (p. 17); satenta mal-réis, sassenta alquiêres (p. 121); trazentos anos ("O frade que steve trazentos anos", p. 154); valhaca (“Joã Soldado", p. 142); "Ê (eu) duvid'a ser mãe pra no parder a minha vergindade. - Sarás virgem antes do parto, sarás virgem no parto e sarás virgem depoi do parto." ("Vida de Nossa Senhora"14, p. 126). Buesco atribui à harmonia vocálica algumas dessas pronúncias (pastana "pestana"; valhaco "velhaco"; p. 91), ou, ainda, devido à influência de $r$, $e$ ou $u$ em posição pré- ou postônica passam a $a^{15}$, como em pardiz por perdiz, barnardu por Bernardo, marcar por mercar, trapeço por tropeço, travão por trovão, tramenta por tormenta (p. 91). Todavia, veja-se esse trecho de uma narrativa da informante Antónia Zefa:

(2) Havia um casal que tinha muito filho e já no sabia quim é qu'havi de ser o pêdrinho. Foi a batezér a criença e prècurou o Senhôr Cruxefequédo pra pêdrinho. [...] A criença pediu ò pai prà inxenér a rezar ò pêdrinho. Inxenou-l'a pedir pão. ("A afelhéda do Senhôr", apud BUESCU, 1984, p. 131; negritos acrescentados)

Embora faça um levantamento das características fonéticas do dialeto de Monsanto e dê explicações como as acima citadas, Buescu não justifica a presença de [e] em pêdrinho ("padrinho"), ou de $[\varepsilon]$ em Cruxefequédo ("crucificado") e em afelhéda ("afilhada"). Essas ocorrências podem ( $i$ ) explicar uma certa alternância entre [e] e [a] na história da língua ou (ii) corroborar a hipótese da existência de um chuá já na fase antiga do português (MENON, 2007, 2010) resultado de uma neutralização no grau de abertura e no ponto de articulação dessas vogais em sílaba átona.

\footnotetext{
${ }^{14}$ Os títulos entre aspas são histórias populares da região, narradas pelos informantes. ${ }^{15}$ A autora remete a Vasconcellos (1901, p. 100).
} 
Igualmente não se justifica dizer que cadê tenha "origem plebeia", como aparece no site da revista Veja, em resposta a uma consulta feita em 30.12.10, por Roberto Leandro: "De onde vem o termo 'cadê', que substitui o 'onde está'?". Veja-se a resposta:

O advérbio "cadê" é uma palavra genuinamente brasileira que, segundo o Houaiss, ganhou seu primeiro registro em 1912, no livro "Contos do Sertão", de Viriato Correa. Trata-se de uma variação mais graficamente esdrúxula - e no entanto, como já se pode afirmar sem susto cem anos depois, indiscutivelmente mais bem-sucedida - de "quede" outro regionalismo brasileiro.

Tanto cadê quanto quedê têm valor interrogativo e são contrações populares de uma mesma expressão: "que é de", ou seja, "que é feito de", "onde foi parar", "onde está?". Pelo menos desde o Modernismo, "cadê" vem reivindicando um lugar no registro culto brasileiro, a tal ponto que hoje mal se percebe sua origem plebeia. [segue exemplificação com parte de "Essa nega Fulô", de Jorge de Lima] ${ }^{16}$

Nem de origem plebeia, pois aparece em Sá de Miranda, o introdutor da "medida nova" 17 em Portugal; nem regionalismo brasileiro e muito anterior ao Modernismo, a forma resultante da gramaticalização de "Que é feito de fulano?", quede (possivelmente com a pronúncia do primeiro $e$ mais centralizado e mais aberto) tem sua fonte no português quinhentista ou mesmo anterior, se atentarmos ao fato de que Sá de Miranda, nascido em 1481, já a utilizou em suas obras.

A citada datação de Houaiss, para o PB, a partir da obra de Viriato Correa, não corresponde às primeiras ocorrências em textos literários, já que uma consulta ao Corpus Davies demonstra que a variante cadê era de uso corrente no séc. XIX e, conforme veremos abaixo, já constava de uma cantiga do folclore brasileiro coletada por Melo Moraes Filho e publicada em 1899 por Viriato Padilha, na coletânea Os roceiros. Nessa, Padilha insere "O Bumba-meu-boi", reproduzido de "Festas do Natal", de

${ }^{16}$ Disponível em: <http://veja.abril.com.br/blog/sobre-palavras/curiosidadesetimologicas/cade-a-origem-de-cade/>; acesso em 31 out. 2014.

${ }^{17}$ Nova concepção em poesia, com diferentes unidades métricas, criação de origem italiana que Sá de Miranda passou a empregar e constituiu moda em Portugal, em substituição à "medida velha", ou poesia tradicional. 
Melo Moraes Filho (PADILHA, 1899, p. 191, nota): em (03), o Amo se dirige a um seu cabra, Matheus (provavelmente ainda escravo, porque na sequência o Doutor se dirige a Matheus, chamando-o de negro, além da menção de um capitão de mato), e este responde à indagação, conforme (04). Ambos usam cadê: o Amo a variante cadê; Matheus emprega a forma gramaticalizada a partir da retomada anafórica: cadê ele $>$ cadele + artigo $o=$ cadêl-o, que os dicionários ainda não registram (nem a variante quedele). Por conseguinte, fica abonado o uso de cadê por dois estratos sociais bem polarizados, no séc. XIX:

(3) Amo -- O' Matheus, cadê o boi? (PADILHA, 1899, p. 185)

(4) Matheus: Olá, plá, olá, / Boio tá p'ra cá, / Boio tá p'ra cá.../ Si minha boio chegou / Eu tá aqui; / E que foi esse / Pur aqui ? / meu xinhô, / Cadêl-o Bastião? / Cadêl-o Fidére? Pra onde fôro? (PADILHA, 1899, p. 185-6)

$\mathrm{Na}$ variedade europeia, a forma quede devia ter ocorrência frequente na segunda metade do séc. XIX, tendo em vista a observação feita por Leite (1887, p. 186), no capítulo "Particularidades de syntaxe acerca da multiplicidade de accepções, que teem certas partes do discurso na lingua portugueza": "A locução relativa interrogativa que é de?... é elliptica e vale por - que é feito de? significando - onde está, que destino tem etc. Ex.: Que é do sól que dê preço a tanto esmero? A. Garrett." Embora ela apareça na forma plena na escrita, por razões de norma prescritiva para esse registro, na fala deveria/poderia aparecer a forma contracta ['kede]. É importante ressaltar que a Grammatica portugueza dos lyceus, de Leite, é extremamente prescritiva e preconceituosa ${ }^{18}$; no entanto, o autor não estabelece nenhuma restrição de uso para a "locução relativa interrogativa que é de?", que dá como abonação uma frase do escritor Almeida Garrett. Logo, pode-se supor que a forma não sofria restrições de emprego, visto que aparecia em obras literárias de autores do porte de Garrett.

${ }^{18}$ Observe-se que, por exemplo, ele denomina vicios de linguagem aos provincianismos: “457. Chamam-se vicios de pronunciação ao modo particular de pronunciar as palavras nas diferentes provincias d'um paiz, vicios que, em regra, se usam com alteração de pronunciação e accentuação, estabelecidas pelas pessoas doutas no estudo da lingua." (LEITE, 1887, p. 211). A seguir, em caracteres menores, insere uma observação: "Obs. Os vicios de linguagem recebem o nome especial de provincianismo." Ainda no capítulo sobre vícios de linguagem, apresenta os neologismos, os arcaísmos e, finalmente, os galicismos, que recebem classificação em três tipos: simples, de dicção e de construcção (LEITE, 1887, p. 214-216). 
Além da comprovação de que já havia, no século XV, a forma contracta quede, na poesia de Sá de Miranda (visto que ele nasceu na segunda metade dos quatrocentos), ela aparece empregada com certa frequência por autores do século XVI, como Antonio Prestes ou o ilustre Camões, no Auto chamado de Filodemo:

(5) Vem ca moço, eu te chamo / quede teu amo (Autos, f. 158r).

Antônio Prestes usa què do no Auto chamado dos Cantarinhos, com sândi entre de e $o$ : de $o$ molde > do molde:

(6) què do molde? não à engeyte / que o bon dela, he bem laurala (Autos, f. 167):

além de què dela no Auto chamado do mouro encantado em (07) forma gramaticalizada de retomada anafórica, ou què da, no Auto da Sioza, em (08), com sândi entre de e $a$ : de a volfa criada $>d a$ volfa criada:

(7) fer. Pois què dela, gri. ela vira / que eu the faley da jenela (Autos, f. $133 \mathrm{v})$

(8) dou. E què da volfa criada / mo. heja cafada". (Autos, f.116v):

Em outro auto de Prestes, o dos Dous hirmaos, além de empregar què dela (Autos, f. 76v): "cio. Senhora onde efta, què dela / ela. Senhor eis me aqui", esse dela não é retomada anafórica: é forma tratamento ao interlocutor (algo frequente no teatro pós-vicentino, conforme salienta José Camões $(2007,2010)$ ), pois quem responde é a própria mulher (ela), que se dirige ao marido usando "Senhor".

No texto abaixo, no trecho do Auto chamado da Sioza feyto por Antonio Prestes, igualmente publicado em 1587 (Autos, f. 121v-122r), diálogo entre Grimanesa (gri.), criada da "molher sioza" (mo.) e entre essa e Fernando (fer.), moço de seu marido ${ }^{19}$, aparecem várias expressões de como se indagar por alguém, sobre "onde?" ou “como está?": vlo, que de, quede, què dele. Como podemos constatar, coocorre ainda com as novas variantes gramaticalizadas a antiga forma $u l o$. Essas variantes são usadas pela ciosa (ciumenta), que pergunta pelo marido e está enfadada com o criado, Fernando, que tergiversa em responder onde o marido

${ }^{19}$ Itálicos e negritos acrescentados; os números foram acrescentados aos versos para facilitar a leitura, em caso de desformatação da ordem, nas colunas. 
se encontra. Inicialmente, a mulher ( $m o$ ) começa perguntando com vlo, depois emprega què dele, a seguir duas vezes que de. Irritada, porque o criado se faz de desentendido, ela repete os três modos de uma só vez (verso 26 do exemplo (09), retomando ainda o quede no verso 27).

(9) gri. Ia vẽ, feñora. mo quẽ veio (1) gri. Fernando, mo. fernãm defcãfa (2) venha embora, que efperança (3) tantoa defanfa o correo (4) como o principal que a canfa (5) fernãdo, fer. feñora, mo. aprefa (6) nam acabas de chegar (7) fer. Ho como fabe o vagar (8) voto a mares què gram pefa (9) mo. Vlo, fer.deixeme affentar (10)

mo. Què dele, fer. como efte dedo (11) me doy, ifto he fiatica (12) mo. Que vida efla tam freimatica (13) vẽ, fer. ey đ morrer muito cedo (14) para que curar de mais pratica. (15) mo. Olhayme que razam efla (16) moço que de teu feñor (17) fer. Como me doy a cabeça (18) quẽ lhe ora vira efta dor (19) mo. Se fe vio quẽ mais padeça (20)

Quem ja feu giro acabafle (21) que de teu feñor Fernando (22) fer. Señora eftaua efperando (23) que por ele perguntafe (24) mo. eu que teftou perguntando (25) fer. Por. [mo]. vlo, què dele, vem (26) diga quede teu feñor (27) entendela a homem de bem (28) [fer]. joga em cas de mercador (29) perde nam ganha vintem (30) Diz que lhe mande dinheyro (31)

Assim, o exemplo (09) nos dá provas da existência de concorrência de formas, em pleno processo de variação, no domínio semântico de "perguntar por alguém, por alguma coisa", que inclui o antigo interrogativo $u l o$, resultado da gramaticalização do advérbio $u$ (proveniente do latim ubi que designava lugar, "onde", confundido e superado posteriormente em português por onde, do latim unde "lugar de onde"), mais o artigo o ou $a$. Essa gramaticalização de ulo deve ter ocorrido quando a forma do artigo ainda era lo, la.

\section{A gramaticalização de "Que é feito de fulano?"}

Tem sido comum criticar Meillet (HEINE et al., 1991; HOPPER; TRAUGOTT, 1993, entre outros) sobre o fato de ele se ater ao domínio lexical ao afirmar que gramaticalização é "a passagem de uma palavra autônoma ao papel de elemento gramatical” (MEILLET, 1982 [1912], p. 131). No entanto, no próprio texto "L'évolution des formes 
grammaticales"20, Meillet trata de grupo de palavras e distingue palavras principais de acessórias, fazendo referência a graus intermediários entre as duas: "Et il y a tous les degrés intermédiaires entre les mots principaux et les mots accessoires" (MEILLET, 1982, p. 135). Além disso, ele discorre acerca do efeito da frequência de uso sobre o valor expressivo das (novas) formas linguísticas ou da combinação de palavras:

A chaque fois qu'un élément linguistique est employé, sa valeur expressive diminue et la répétition en devient plus aisée. Un mot n'est ni entendu ni émis deux fois exactement avec la même intensité de valeur. C'est l'effet ordinaire de l'habitude. Un mot nouveau frappe vivement la première fois qu'on l'entend; dès qu'il a été répété, il perd sa force, et bientôt il ne vaut plus qu'un élément courant depuis longtemps. Ceci est plus vrai encore d'un groupe de mots: la plupart des gens parlent e surtout écrivent au moyen de formules toutes faites, de "clichés"; aussi deux mots usuels apparaissent-ils presque neufs s'ils sont rapprochés pour la première fois ou si, du moins, on les rapproche alors qu'ils ne sont pas rapprochés d'ordinaire; Horace a signalé depuis longtemps ce que vaut une alliance de mots nouvelle, une iunctura noua; il l' a montré par beaucoup d'exemples. [...] Si donc un groupement de mots devient fréquent, s'il est souvent répété, il cesse d'être expressif, et il est reproduit de plus en plus automatiquement par les sujets parlants. [...] De ce qu'un mot est groupé avec un autre d'une manière qui tend à devenir fixe dans certains cas, il résulte pour ce mot la perte d'une partie de son sens concret dans ces constructions. (MEILLET, 1982, p. 135-136)

Assim, vamos tratar do processo de gramaticalização da frase "Que é feito de fulano?" até chegar a pronome interrogativo cadê e variantes e, depois, seguir mais adiante e constituir a locução cadê que, de uso mais restrito.

A maioria das explicações sobre cadê / quedê, dá a frase "Que é feito de?" como origem desse advérbio / pronome interrogativo, ou,

${ }^{20}$ A indicação de páginas se refere à reimpressão de 1982, da edição de 1975; o texto, originalmente, foi publicado em: "Scientia (Rivista di scienza), vol. XII (1912), $\mathrm{n}^{\circ}$ XXVI, 6” (MEILLET, 1982, nota I, p. 130). 
evitando dar uma classificação morfológica mais precisa, um site da internet o denomina de "expressão interrogativa":

Notas (pronomes)

(01) Na expressão interrogativa Que é de? Subentendese a palavra feito. Que é do sorriso? (=Que é feito do sorriso?), Que é dele? (=Que é feito dele?). Nunca se deve usar quédê, quedê ou cadê, pois essas palavras oficialmente não existem, apesar de, no Brasil, o uso de cadê ser cada dia mais constante. ${ }^{21}$

Embora com restrições de uso ("familiar, popular"; mas altamente prescritivas, no site acima citado), três das variantes decorrentes do processo de gramaticalização - cade / quede / quedê - encontram-se dicionarizadas ${ }^{22}$, como no Aurélio: na p. 247, cadê aparece como variante de quede; este constitui verbete na p. 1169:

Quede. [De que é (feito) de.] Bras. Fam. e pop. Forma empregada interrogativamente no sentido de: que é de? onde está? : " $\mathrm{Q}$ u e d e aquela menina chamada Naná, que tremia de medo com as histórias de lobisomens e de mulas-sem-cabeça?" (Ciro dos Anjos, Montanha, p. 335) [Var. quede (ê), quedê, cadê.]

ou no Dicionário da Academia Brasileira de Letras (consulta online, em 31.10.14): cadê, quedê). No Dicionário Houaiss encontramos dois verbetes, cadê (p. 556), com a informação de que é "forma brasileira, informal, melhor que quede", com significado de "que é de"; "onde está". Buscando a forma quede, nos deparamos com a informação de que a primeira atestação é em Viriato Correia, na obra Contos do Sertão, de 1912. A classificação morfológica é a de "expressão interrogativa", cujo significado é "que é de"; "onde está", "cadê”. Dá como fonte etimológica o português "que é feito de", com crase de - e-e-ê $[\text { sic }]^{23}$; depois, por

${ }^{21}$ Disponível em: <www.tudosobreconcursos.com>; acesso em 31 out. 2014.

${ }^{22}$ Isso contradiz a afirmação daquele site, de que "essas palavras oficialmente não existem".

${ }^{23}$ Um dos pareceristas anônimos sugeriu que, onde eu havia usado a palavra crase para indicar a fusão de duas vogais, deveria usar elisão, por considerar que crase corresponde à fusão de "duas vogais idênticas". Para evitar polêmica sobre o fato de serem vogais idênticas os as da chamada crase entre preposição e artigo, satisfiz a demanda do parecerista, porque alguns autores consideram elisão a contração da vogal final de uma 
expressividade, a acentuação se deslocou para a sílaba final: quedê, e daí, cadê.” (p. 2352). Apesar de essas fontes registrarem as variantes como brasileiras, a sua origem está em textos do PE (português europeu).

Verificando a quantidade de variantes presentes em diferentes momentos da língua portuguesa, tanto no $\mathrm{PE}$ como no $\mathrm{PB}$, e analisando a trajetória de cada uma delas, vamos falar em processos de gramaticalização, como justificamos na introdução. $\mathrm{Na}$ realidade, abordar o fenômeno como sendo decorrente de um só processo linear de gramaticalização não dá conta da complexidade das formas em uso, nem da sua fonte mais direta: quedele tem origem distinta de quede ou de quedê, por exemplo. Assim, as formas serão abordadas em quatro processos distintos:

(a) da frase para o vocábulo: que é feito de fulano > que é de fulano $>$ qu'é de fulano > quede (fulano) > quede (?) em posição inicial

(b) da retomada anafórica: que é dele $>$ qu'é dele $>$ quedele $>$ quedele o fulano / cadel-o boi?

(c) da variante posicional: quede fulano (interna) > quedê? (posição final, com acento de frase)

(d) da variante fonológica: cadê > cadê que (marcador discursivo)

\subsection{Da frase para o vocábulo}

É possível que o processo de gramaticalização da frase "Que é feito de fulano" tenha ocorrido em virtude de essa pergunta passar a ocorrer mais frequentemente, em substituição a outra pergunta que se arcaizou, em decorrência da perda do advérbio $u$ ("onde"), que aparece ainda em Sá de Miranda, na écloga Basto: "Bieito. Não sei que demo te viste, / que tu não pareces Gil. / Amigo, onde te sumiste? / Ulo aquele grande amigo, / de limpos bofes lavados, / daquele bom tempo antigo?" p. 154). Essa perda é assinalada por Said Ali, quando analisa a sorte dos advérbios U (HU), ONDE, DONDE, AONDE, na língua portuguesa:

921. A vulgarização de donde, tão expressivo para denotar procedência, deu lugar a crer-se que o mesmo vocábulo,

palavra com a inicial da palavra seguinte e crase, pelo menos quanto aos exemplos aduzidos, seria interna, o que não explicaria a chamada crase a $+\mathrm{a}$... No entanto, isso não foi possível na citação do dicionário Houaiss. 
desprovido da característica partícula de, era tão-sòmente o sinônimo do advérbio $u$. A esta modificação semântica precedeu naturalmente um período de confusão, de que dão eloqüente testemunho êstes passos do Livro de Esopo: Pol-a [a linha] darredor da arvor domde a aguya tijnha sseus filhos (19) - Chegou a rraposa ao pee da arvor omde a aguya tijnha sseus filhos (18) - Levou-hos a hũ ninho $h u$ estavam sseus filhos (18).

922. Supérfluo pareceu afinal o advérbio $u$, fadado a desaparecer. Na segunda fase do português antigo vai escasseando o seu emprêgo, até tornar-se raridade na linguagem quinhentista e seiscentista, onde se nos depara combinado com o artigo sob a forma interrogativa ulo (significando "onde é o", "onde está o") e, até, adulo por influência do superfetado adonde, de que adiante falaremos:

E ulas cavallarias que tendes para me levar (Gil Vicente 3, 46) - Onde está o entendimento? Ulo ser e autoridade de fidalgo? (Sousa, Arc., 1, 433) - Adulo o teu malvaisco, Britez filha, e o Solimão? (Francisco Manuel de Melo, Fid. Apr. 25) - Pois adullos mariolas? (ib. 52)

923. Ulo podia vir seguido de um demonstrativo como em Gil Vicente, 3, 67: Hulos esses namorados? (SAID ALI, 1964, p. 185)

No entanto, a forma vlo coocorria ainda no século XVI, com què dele, que de, quede, como atestam os versos retirados de (09), acima citado, do Auto chamado da Sioza feyto por Antonio Prestes, publicado em 1587. Inclusive, na fala que engloba os versos (26) e (27) ${ }^{24}$, a personagem enumera três deles, para intensificar e reforçar a pergunta:

mo. Vlo, fer.deixeme affentar (10)

mo. Què dele, fer. como efte dedo (11)

moço que de teu feñor (17)

que de teu feñor Fernando (22)

fer. Por. [mo]. vlo, què dele, vem (26)

diga quede teu feñor (27)

${ }^{24}$ (26) e (27) correspondem à numeração interna dos versos do exemplo (09). 
No Auto das Capelas (anônimo do séc. XVI; em Teatro XVI, I, tomo II), também há coocorrência de vários recursos do domínio funcional "indagar a respeito de pessoas e coisas", incluindo o verbo ser com o advérbio lá, em (11):

(5) Aires do Quintal. Meu costume é nestas feiras / ver a cousa se me faz. / Qu'é do moço? / Vilão. Vem cá, Brás. (p. 66)

(6) Aires do Quintal. É lá o senhor? É lá? / Lopo d'Azevedo. Pois onde quereis que seja? (p. 62).

(7) Clérigo. Pois que o tomemos. / Qu'é do vosso fato velho? / Aqui debaixo o trazemos. (p. 92)

(8) Aires do Quintal. Beijo as mãos do embuçado. / Nam falais? U-la justiça? ( p. 90)

(9) Pai. Qu'é de Velez? Dize moura. (p.94)

O uso de onde aparece no Auto de Dom André, de autor anônimo do século XVI, ainda com o verbo ser:

(10) Senhora. Onde é vosso senhor, Valadares? / Pajem. Certa, senhora, não sei. / Se não é com André Soares, / será falar a elrei. / Não erra um destes lugares. (p. 40)

ou com forma mais arcaica ainda (Sê, de sedere = está), no Auto de Santo António (p. 32):

(11) Cantá eu quero-o chamar: / Sê aqui António Godinho?

Mas também já aparece pergunta com o donde, seguido de está (17) ou fica (18), além de uma variante menos usual, qu'é em (19):

(12) Dom Belchior. Donde está minha senhora? (Auto de Dom André, p.68)

(13) Duarte. [...] donde fica o malvado / do velhaco de teu amo? (Auto dos Escrivães do Pelourinho, Teatro tomo I, p. 109.)

(14) Pero Vaz. Ora bem e qu'é tua ama? / Ratinho. Si, noss'ama sê lá dentro. (Auto do Caseiro de Alvalade, Teatro XVI, tomo I, p. 79)

No entanto, dentro da limitação do corpus utilizado neste estudo, foi só na Comédia Eufrosina, de Jorge Ferreira de Vasconcellos (mas nessa época já era de largo emprego a forma contrata qu'e de, também 
empregada pelo autor em (24)) que encontrei abonação para a frase completa que deu origem à forma nova, embora em ordem diferente (20). Além disso, Vasconcellos usa o verbo ser com sentido de estar em (21), e faz um questionamento com o verbo dar novas, em (22):

(15) $G A$. Sabeis quem anda agora muito perdida e desbaratada? Hũa que morava na Betesga e estava por Troilo de Froes. $C A$. E delle que he feito? $G A$. Gastadissimo destes males: e de tudo vaise este anno aa India. (VASCONCELlos, 1918, p. 241).

(16) $C A$. Como se lançou a perder este mancebo, e logo tinha muito bem de seu e gastou tudo com essa molher e em jogo. Dizei me, señor, hũa mulata / muito preites que morava na rua dos Cavides, que nos festejou muito, se vos lembra, quando fomos aos touros d'Almada onde he lançada, terça inda por seus amigos? $G A$. Antes da minha partida jantei na sua pousada, e disselhe que vos vinha ver, quiseravos escrever, deu me cem mil encomendas pera vos, que nam avia no mundo tal homem. (VASCONCELLOS, 1918, p. 241-242)

(17) $C A$. Somos grandes compadres e tem ella por mi feito alguns negocios bons. Lembravos da confeite[i]ra, que novas me dais della? (VAsconcellos, 1918, p. 242)

(18) Pai. Qu'é de meu filho, Gil Vaz? / Gil Vaz. Lá vai de saúde e paz / de França pera Aragão / como físico sorgilião (Auto dos Enanos, Teatro, p. 193).

(19) CA(riophilo). Que'é de vos, velhaco, que nam apareceis, nunca mais me viestes ver desque viemos. (VASCONCELLOS, 1918, p. 72)

Em (21) a indagação diz respeito a uma mulata "muito preites", isto é, a personagem estava interessada em obter informações a respeito das atividades atuais da mulata (a frase terça inda por seus amigos significa provavelmente que ela servia de intermediária, terceira, para certos assuntos) e não propriamente saber onde ela estava. $\mathrm{O}$ mesmo conteúdo informacional, de saber como está, o que faz, é solicitado a respeito da confeiteira, em (22). O mesmo tipo de pedido de informação, sobre não só onde anda, mas sobre o que faz, aparece em (23). No exemplo (24) Que'e de vos, velhaco, a pergunta não é para saber por onde anda o amigo, mas equivale a uma censura, ou pedido de explicação visto que a personagem recrimina o amigo (velhaco) por 'não aparecer nem vir vê-lo'. 
Podemos constatar, pelos exemplos, que houve variação não só de formas para se indagar a respeito de alguém, mas também de acréscimo ou mudança de conteúdo apresentado pelas novas expressões gramaticalizadas e que a forma quede (embora em alguns casos ainda escrita como que'é ou qu'é) já havia se tornado habitual no séc. XVI.

Com base nessas abonações, vemos que o processo de gramaticalização já se completava na parte oral, com erosão da massa fonética (que é de > quede) e também se expandia na aplicação da cadeia da metáfora conforme estabelecida por Heine et alii, (1991, p. 157):

$$
\text { pessoa }>\text { objeto }>\text { processo }>\text { espaço }>\text { tempo }>\text { qualidade }
$$

visto que, do uso inicial para perguntar por alguém, usando-se a escala (cline) a partir de pessoa: do nome próprio (Bastião, Dona Rita) para a qualidade da pessoa (amo, criada, moço) e, daí, a retomada anafórica (de mi, dele, dela), passou-se para perguntar sobre animais (boi); na sequência, estende-se o uso para objetos (molde). Há também uma mudança de significado, porém não perda, no uso mais abstrato constatado em (21)-(23) e especialmente em (24) que, vimos, equivale a uma censura, portanto, como processo, visto que a personagem não indaga sobre alguém ausente, mas se dirige diretamente ao interlocutor para censurá-lo por andar desaparecido e não manter contato com os amigos.

Pode-se constatar que a gramaticalização em estudo fornece exemplo de desdobramento interno à parte mais alta da cadeia acima citada, de pessoa: da categoria mais concreta, mais definida, que é o nome próprio, passa-se a nome comum (qualidade, posto da pessoa na hierarquia social) e à retomada anafórica (mais gramatical).

Mas há também um animal: então, teríamos de pensar a primeira categoria de maneira hierarquicamente mais alta: [+animado], o que possibilitaria incluir duas subcategorias: [+ animado] e [+ humano] com outras subcategorizações [+humano, +animado, +individualizado (nome próprio)] e [+humano, +animado, +comum] e [+ animado - humano], antes de passar à categoria objeto [- animado], mais gramaticalizada. Deve-se também questionar se e até que ponto a retomada anafórica ainda se encaixaria em pessoa ou se, por ser mais abstrata, já que opera com conceitos estabelecidos de relação com um referente anteriormente mencionado, corresponderia à terceira etapa da cadeia: processo. 


\subsection{Da retomada anafórica}

E foi no Auto de Dom André que encontrei a construção que seria formada com retomada anafórica de um sintagma nominal anterior: qu'e delle. Em (25) temos o sintagma nominal (ou locução nominal) o amo, seguido da pergunta com retomada anafórica: qu'é dele?:

(20) Senhora. Nunca mor acerto vi. / Se mais cedo falara nele, / mais cedo fora ele aqui. / Pois, e $o$ amo, qu'é dele? (Auto de Dom André, p. 46)

Entretanto, no mesmo período (século XVI), na Comédia Eufrosina (em prosa, cuja data de publicação inicial seria 1555, mas composta muito antes, entre 1542 e 1543, conforme o Dicionário cronológico de autores portugueses, p. 211), já se encontra a forma gramaticalizada como simples recurso de pergunta para saber "onde está?" ou “quem é?", isto é, como localizador espacial, dêitico. Em (26) Sílvia pergunta a Eufrosina se ela tem interesse em conhecer um servidor ("cortejador, namorado") da moça Vitoria. Eufrosina responde com a indagação "Que'e delle?" que significa que ela quer que Sílvia mostre, aponte quem é (dentre vários que estão em cena). Sílvia aponta para um rapaz que está calçando "borzeguis", o qual não causa boa impressão em Eufrosina, que o identifica como alguém rude (vilão), que bate em mulher:

(21) SIL(VIA). Quereis ver señora um servidor da nossa Vitoria.

EUF(ROSINA). Que'e delle?

SIL. Aquelle dos borzeguis em jejum de carneiro.

$E U F$. Mal assombrado he o vilão, quanta pancada the aquelle dara. (VASCONCELLOS, 1918, p. 221)

E em (09), como vimos, ocorre què dele (verso 26) como retomada anafórica do verso (22), que contém em si a forma que de seguida do SN teu feñor: "que de teu feñor Fernando".

A forma gramaticalizada quedele incluiu, da forma frasal primitiva, o pronome ele, que acabou por perder todo o seu conteúdo referencial (bleaching, conforme Hopper e Traugott (1993)), passando a constituir simplesmente uma sílaba do novo pronome / advérbio. Sendo assim, essa nova forma admite, na sequência, usar uma LN começada por artigo: "Quedele o guarda-chuva que estava aqui?" Isso não seria possível se a 
leitura fosse feita de modo a preservar os elementos constituintes primários: "Que é dele o guarda chuva que estava aqui?" Essa não é uma frase bem constituída na língua portuguesa. Prova da opacidade completa desse ele presente na frase original é que a LN pode estar no feminino: Quedele a patroa ? $^{25} \mathrm{O}$ exemplo do séc. XIX, do $\mathrm{PE}$, atesta essa possibilidade de coocorrência, visto que a leitura de "que é delle o freguez" deve ser "quedele o freguês":

(22) Cinco minutos depois d'isto, entra Tinouco com um maço de cartas na mão.

- Que é delle o freguez?

- Está lá dentro.

- Chamem-o aqui. (ARAÚJO, 1871, p. 116)

Também essa deve ser a interpretação dos exemplos (28)-(30), do séc. XIX, retirados do Corpus Davies, embora as grafias sejam distintas (que é dele o; quedê lo):

(23) - lá, não vou lá, não vou lá! - que é dele o teu camarada? (Corpus Davies, séc. XIX, 1.18. Varnhagen: Ensaio)

(24) E quedê lo Seu Majó? - É o quê, menino? Hão de vi três pessoas para mais. (Corpus Davies, séc. XIX, 2.18. Oliveira: Guidinha) (25) - [...] - E quedê lo gado? Já se foram os tempos das fazendas de mil cabeças. (Corpus Davies, séc. XIX, 4.18. Oliveira: Guidinha)

As dificuldades de transposição para o escrito de formas ainda não dicionarizadas (que é o caso de quedele) conduz a soluções gráficas bizarras: não se justifica a forma lo antes de Seu Majó e de gado, visto não haver nenhuma razão fonética para aparecer esse lo em lugar de $o$. Simplesmente, optou-se por uma solução gráfica que teria razão de

\footnotetext{
${ }^{25}$ Devido ao fato de não ter a pretensão, nem o tempo, de fazer pesquisa exaustiva diacrônica das ocorrências das formas em tela, no corpus deste trabalho não foi flagrado nenhum dado de quedele mais SN no feminino (embora tenha aparecido isoladamente, conforme o exemplo (07): Pois què dela), o que não significa que não possa ocorrer: exemplo pessoal é o meu uso (regular) dessa forma, que aprendi em criança e que se ouve na minha região: “Quedele a toalha que eu deixei aqui?". Há, no entanto, uma ressalva a fazer: parece pouco provável, mesmo com corpus mais alargado, que se vá encontrar a forma cadela, por razões evidentes de eufonia.
} 
ser na língua antiga, quando o pronome objeto ainda era lo (seja por razões etimológicas, seja por condicionamento fonético, como após um infinitivo, em que haveria um metaplasmo, transformando o $r$ do infinitivo em $l$, diante do pronome). Mas isso não encontra justificativa na língua do séc. XIX. Porém, como registrar essa forma nova, resultado da contração de que é dele? A solução gráfica até pode parecer interessante; porém, não se pode ler quedê lo gado como [ke."de.lo."'ga.do] ${ }^{26}$. A sua leitura deve ser [ke."de.le. o."'ga.do].

Idêntica leitura deve se realizar também com as ocorrências da variante com cadê: cadele, com registro já no séc. XIX:

(26) era a exclamação da Carolina, toda solicitudes: -- Cadê lo Secundino? (Corpus Davies, séc. XIX, 4.18: Guidinha, Oliveira)

(27) Casaria lá para janeiro. Cadê o Secundino? perguntava a si mesma. Nem mais se lembrava do antigo cavalariano, cansada de sofrer. (Corpus Davies, séc. XIX) 4.18: Guidinha, Oliveira)

Oliveira emprega as duas variantes de cadê com o mesmo SN: "Cadê o Secundino?" em (32) e "Cadê-lo Secundino?" em (31). A sequência "Cadê lo Secundino?" deve ser lida [ka."de.le.o.se.kũ."di.no] e não [ka."de.lo.se.kũ."'di.no]. Também aparece outra grafia distinta nos dois dados do Bumba-meu-boi do exemplo (04), "Cadêl-o Bastião?" e "Cadêl-o Fidére?", cuja leitura deve ser [ka."de.le.o.bas.ti."'ãw] e [ka."de. le.o.fi."'de.re].

\subsection{Da variante posicional}

O dicionário Houaiss (2001, p. 556) dá como fonte etimológica de cadê "port. que é (feito) de, com crase de -e-e-ê (sic); depois, por expressividade, a acentuação se deslocou para a sílaba final: quedê, e daí, cadê" Como não se explica de que natureza é essa "expressividade", vamos propor uma hipótese, bastante plausível, a da variante posicional. Na cadeia de modificação fonética, a forma quede vinha acompanhada de nomes, pronomes ou de SNs.; portanto, em posição interna na frase, conforme os exemplos (33) e (06)-(08), aqui renumerados (34)-(36):

${ }^{26}$ Lembrar que a intensidade de LN é dois ["]; a de frase é três ["'], conforme Back e Mattos (1975). 
(28) Q'é de mi, se não sou lá / e cá comigo não vou? (SÁ DE MIRANDA, 1960, p. 5)

(29) què do molde? não à engeyte / que o bon dela, he bem laurala (Autos, f. 167)

A leitura desses dois dados seria, respectivamente: ["ke.de."'mi] e ["kع.do."'mol.de]. A posição interna favorece a hipótese de que, nessa época, a pronúncia de quede ainda seria paroxítona. Mas já podia acontecer que o acento fosse deslocado para a sílaba seguinte, como em (07), aqui retomado como (35): ["ke. "I' $\mathrm{d} \varepsilon$.la], o que poderia, de uma certa forma, ter favorecido a pronúncia oxítona quedê, o que não seria possível com uma sequência como em (08), retomado aqui como (36), em que a sílaba final de quede permanece átona, porque se funde com sílaba átona da palavra seguinte: ["ke.da.'vo.sa.kri."'a.da].

(30) fer. Pois què dela, gri. ela vira / que eu lhe faley da jenela (Autos, f. $133 \mathrm{v}$ )

(31) dou. E què da volfa criada / mo. heja cafada". (Autos, f.116v)

Por conseguinte, enquanto o uso de quede foi em posição interna, a forma paroxítona teve condições de ser preservada. Todavia, temos a seguir (37)-(39), dados obtidos na listagem de procura de ocorrências de quedê nos séculos XIX e XX, no Corpus Davies. Eles apresentam formas oxítonas de quede (pois estão acentuadas graficamente com circunflexo), mesmo seguidas de SN (este homem), nome (dona Rita) ou pronome (ele), e remontando a José de Alencar. Duas possibilidades de interpretação que ficam por verificar: (i) problema de edição (acentuação moderna com atualização ortográfica de texto mais antigo) ou (ii) comprovação do fato de que a forma oxítona já estava consolidada desde a primeira metade do século XIX:

(32) Retorquindo assim ao Pinta, dirigiu-se o Barroso à vendeira: Quedê este homem? - Ele não está, nhor, não! - Onde foi? - Na vila, nhor, sim. - Quando volta? - Volta logo. - O diabo o leve e mais quem o ature. (Corpus Davies, Til, José deAlencar, s/d)

(33) EDUARDO (Entrando pela esquerda) - Adeus, Malaquias. Quedê dona Rita? Já está levantada? MALAQUIAS - Tá lá dentro, sim, sinhô. EDUARDO - E dona Laudelina? MALAQUIAS - Inda tá drumindo, sim, sínhô. (Corpus Davies, Mambembe, Artur de Azevedo, s/d) 
(34) Quedê ele? - Quem? - perguntou-lhe a mulher. - Ele, esse Cassi - fez ele com os punhos cerrados, a errar o olhar desvairado, pelos quatro cantos da sala. - Mas que há, homem? - fez a mulher assustada. - Lê isto. (Corpus Davies, Clara dos Anjos, Lima Barreto, s/d)

Em posição interna, lembremos, o acento prosódico pode ter intensidade dois ["], no máximo: no dado (33) a sequência "quedê este homem" teria duas LNs; a primeira com intensidade 2, e a segunda, por ser fim de frase, receberia intensidade 3: [ke."de.'es.te. "'o.mẽ]. O dado (34) corresponde a [ke."de.'do.na."'ri.ta]; e em (35) a leitura seria [ke."de."'e.le]

Entretanto, qualquer que tenha sido o período (ainda não delimitado), a partir do qual se começou a empregar isoladamente o pronome/advérbio interrogativo, conforme o dado (40), permanece o fato de que basta deslocar qualquer palavra átona, como o que, para a posição final da frase, para que esse vocábulo receba o acento de frase, que é de grau 3 ["']. Graficamente, essa situação requer que a palavra átona seja acentuada: o que, no caso, receba acento circunflexo: "Para quê?", a fim de marcar a intensidade de final de período ou frase.

(35) - Então onde é que está a coisa? Quedê? Sua mentirosa! - Perdão, titia! Eu não faço mais! (Corpus Davies, Meu destino é pecar, Nelson Rodrigues, 1944)

Então, vemos que a chamada "expressividade", mencionada no dicionário Houaiss, deveu-se a um deslocamento da posição: de interna para final de frase. A frequência de uso de duas perguntas como em (40), uma completa "Então, onde é que está a coisa?" seguida de outra reduzida, "Quedê?", pode ter sido a via pela qual se implementou na língua a forma quedê e, por consequência, também cadê.

Do ponto de vista da gramaticalização, caberia indagar se se aplicaria a esse Quedê? que constitui uma frase, o princípio da unidirecionalidade, conforme exposto por Heine et al. (1991, p. 149-150):

A third characteristic which is implicit in these definitions and has frequently been mentioned as an intrinsic property of the process is that grammaticalization is unidirectional, i.e. that it leads from a "less" to a "more grammatical" unit but not vice versa. 


\subsection{Da variante fonológica}

Entretanto, a gramaticalização de cadê não parou nas formas/ significados mostrados em 3.2 e 3.3. Se os processos de gramaticalização acima expostos remontam a mais de dois séculos, o mesmo não se pode dizer do último processo, o da passagem de cadê para cadê que. Este parece ser localizável na segunda metade do séc. XX, conforme dado colhido pelo Corpus Davies, de obra publicada em 1993:

(36) - Vocês não estão vendo que esse punhado de paulistas não tem condições de lutar contra o governo? - O quê? Levindo, larga mão de falá besteira. O governo já mandou pra cá sordado e avião de ruma, cadê que acabou com os paulista? (Corpus Davies, 19:Fic:Br:Cabral: Xambioa ${ }^{27}$ )

Segundo abonação do dicionário Michaelis online, existe um outro significado para cadê: "quem disse que". No entanto, a frase usada para abonar esse sentido não contém só cadê, mas sim "cadê que!", conforme atesta o Dicionário de português online ${ }^{28}$ :

cadê

ca.dê

contr Forma popular interrogativa de: "que é de?" Equivale a "onde está?" (em São Paulo, usa-se também quedê, no mesmo sentido: Cadê (quedê) a vassoura?) e a "quem disse que": Cadê que ele pode!

É possível ouvir em algumas regiões (depoimento oral de aluna mineira e de aluna paulista) essa forma cadê que, equivalente a esse "quem disse que", mas também para expressar dúvida. Dias atrás, uma professora universitária baiana, contando uma história da infância, disse: "Mas cadê que eu ia contar quem quebrou o vaso?" Na minha região, o correspondente a esse uso de cadê que seria capaz que: "Capaz que ele pode!" com o significado de se pôr em dúvida a capacidade ou possibilidade de alguém fazer alguma coisa ou de acontecer algum fato: "Capaz que chova!".

${ }^{27}$ Consegui localizar a data (1993) e a editora (Record) de publicação do livro de Pedro Correa Cabral, Xambioá: Guerrilha no Araguaia.

${ }^{28}$ Disponível em: <www.michaelis.uol.com/moderno/portugues/definicao/cade>; acesso em 31 out. 2014. 
Na gramática atrás mencionada o autor tem um capítulo sobre palavras expletivas. Nele, faz referência a diversas palavras, como o verbo ser, seguidas de que dito expletivo, porque se poderia "supprimir sem alterar o sentido" (LEITE, 1887, p. 156). Depois de mencionar que, lá, mais, não, o pronome reflexivo, como palavras expletivas, encerra $\mathrm{o}$ assunto com:

Exemplos de phrases expletivas. Se soubessem quão negra era a predestinação do poeta, por ventura que essa especie de culto se converteria em compaixão. A. Herculano. $O$ Monasticon. - Certo que não sei eu outra. Rodrigues Lobo. Côrte na aldêa. Quasi que - morria de alegria. (LEITE, 1887, p. 156)

O processo de adição da "partícula que" a "certos advérbios e alguns particípios" é mencionado por Said Ali (1964, p. 104) "para dar origem a conjunções de nova espécie". Em outro passo, justifica o fato com a perda de significado e generalização de uso do que proveniente do latim quod:

1105. [...] O esquecimento, fator essencialíssimo na evolução da linguagem, transformou, em tais construções, o valor primitivo de quod ora em conjunção causal, ora em partícula tão inexpressiva que já no latim da decadência veio a servir de mero expoente das orações subordinadas cujo caráter não se definisse por meio de outra partícula. Herdeira de quod assim diferenciado é a conjunção portuguêsa que, com a variante $c a$ (qua) usada no falar antigo para exprimir o sentido causal. [...]

1108. Êsse processo creador de novas conjunções ou locuções conjuncionais revela-se sobremodo fecundo nas combinações de advérbios e dizeres de caráter adverbial com a partícula que: a fim que (português hodierno a fim de que), sem embargo que, contanto que, ante(s) que, depois que, etc. (negrito acrescentado).

1109. Nestas, como em outras locuções conjuncionais, o elemento advérbio nada mais é que um vocábulo deslocado de uma oração para outra. Devia modificar um verbo, mas afasta-se dêle , emigra da respectiva oração, atraído por uma partícula, à qual se une, resultando desta liga uma conjunção de nova espécie. Basta ver o histórico do adventício ainda em ainda quando e ainda que. (SAID ALI, 1964, p. 221-222) 
O processo narrado por Said Ali descreve o tipo de composição em que entra um que expletivo, ente eles, "advérbios e dizeres de caráter adverbial com a partícula que". Cadê que se encaixa nessa descrição, nessa espécie de "dizeres de caráter adverbial", denominação eufêmica para se referir a classe morfológica inexistente, como é o caso dos marcadores discursivos, que tem um certo caráter adverbial, por introduzirem, modificarem o conteúdo das frases, introduzindo nuances interpretativas: o né?, MD emitido para se verificar se o conteúdo da mensagem chegou ao receptor, não tem essa função?

No Corpus Davies estão arroladas mais duas ocorrências de cadê que, do séc. XX, localizadas em entrevistas orais:

(37) Fiz muito show com esse CD do Vinícius e está no meu repertório até hoje, regravei nele arrastão, uma música que adoro, e que cantei com mamãe e Edu Lobo no último dia do show Reencontro. Partimos pro "Sambas e Bossas". Queríamos fazer um CD de inéditas, eu já estava com músicas da Fátima Guedes. Lucina e Zélia Duncam, Lenine, Fred Martins. Mas cadê que eles queriam lançar? Aí resolvi fazer o "Sambas e Bossas", [...] já que a CBS/ Sony não relançou em CD esse LP. Solange Castro - O disco é uma obra-prima, Claudinha, sem dúvidas. (Corpus Davies, 19:Or:Br:Intrv:Web)

(38) Aí ele emitiu um som que é o que ele sentia ser o meu. Passou esse som pra mim, mostrou o som e falou: agora volta para o corpo concentre-se nesse som..mas é capaz de você não se lembrar dele.. Pô, Marco, eu entrei no corpo. Na hora em que entrei eu me lembrei que eu tinha um som, mas cadê que eu lembrava qual som era? [risos]. (Corpus Davies, 19:Or:Br:Intrv:Web)

Como classificar esse cadê que? Ele se formou, aparentemente (conforme exposto acima), como muitas outras conjunções do português (pois e pois que; segundo e segundo que; enquanto e enquanto que) ou como os advérbios quase e quase que, com o acréscimo de um que não modificador do significado, nem ditado por regras sintáticas (como é o caso de para e para que: a primeira forma é empregada com verbo no infinitivo e a segunda quando o verbo está em forma flexionada em tempo/modo). Parece que no caso de cadê que, tanto como em capaz que, retromencionado, a junção passou a constituir uma espécie de marcador discursivo que substituiria uma oração inteira: em (43), "mas cadê que 
eu lembrava qual som era?" poderia ser glosada por "mas você pensa/ acredita que eu não lembrava qual som era?"; "mas quem diz que eu lembrava qual som era?" ou com algum intensificador, como lá: "mas e lá eu lembrava qual som era?". Em (42) o significado parece ser de dúvida: "e quem diz que eles queriam lançar?"

Embora o Corpus Davies seja de uso problemático, quando se quer fazer estudos que envolvam variação e mudança, pelo fato de não se poder saber quantas obras existem para cada século; nem se poder ter acesso à referência bibliográfica completa, com indicação de página da ocorrência, ele foi uma ferramenta útil para se formar uma ideia da quantidade de ocorrências das variantes resultantes dos processos de gramaticalização de "Que é feito de fulano?". A tabela 1, a seguir, ilustra o resultado da busca, em número absoluto de ocorrências:

Tabela 1 - Número de ocorrências das variantes no Corpus Davies

\begin{tabular}{c|c|c|c|c}
\hline Período & Cadê & Quedê & Que é dele & Cadê que \\
\hline Séc. XIX & 09 & 05 & $16(\mathrm{~PB})$ & - \\
\hline Séc. XX & $104(\mathrm{~PB})+02(\mathrm{PE})$ & 02 & $03(\mathrm{PE})^{29}$ & $03(\mathrm{~PB})$ \\
\hline
\end{tabular}

Vemos uma distribuição das variantes, por século (a partir do séc. XIX, que é a data limite a partir da qual os dados sob análise aparecem nas obras que compõem esse banco de dados) e por variedade (PB e $\mathrm{PE}$ ), embora os do PE sejam muito poucos, porque poucas são as obras portuguesas no Corpus Davies. Embora os números sejam absolutos e não se tenha nenhuma distribuição por obra, o que pode significar que, para determinado período, uma só obra tenha contribuído com grande número de ocorrências, há uma predominância da forma cadê para o PB do séc. XX; uma diminuição no uso de quedê; que é dele praticamente desapareceu do PB e a nova forma gramaticalizada cadê que faz sua entrada no PB nas obras e entrevistas do séc. XX. Em contrapartida, que é dele aparece no $\mathrm{PE}$ do séc. XX e, embora o Corpus Davies não registre dado para o séc. XIX, vimos mais acima que nesse século aparece essa forma, conforme exemplo (27). Os dois dados de cadê em texto do PE do séc. XX são as referências ao "brasilês", na citação na seção 1 .

\footnotetext{
${ }^{29}$ Para o PB, apareceram, na listagem do Corpus Davies, sete dados com a sequência que é de: porém, trata-se da forma para referenciar a posse, como por ex., Montello, "que é dele o filho", isto é "“que o filho é dele".
} 


\section{4 À guisa de conclusão}

No tocante à classificação morfológica de cadê, a maioria das consultas na internet mostrou (i) uma falta de segurança em identificar a classe morfológica, com o uso de "expressão interrogativa", locução interrogativa"; "forma popular interrogativa"; (ii) classificação como advérbio interrogativo; (iii) classificação como pronome (mais rara: só duas vezes). Como muitas outras palavras, cadêlquedê/quedel quedele/cadele podem receber mais de uma classificação, de acordo com o contexto em que são empregadas. Tomemos como elemento de comparação o caso de onde, que pode ser classificado como advérbio (ou será pronome interrogativo?) em "Onde fica a prefeitura?", como pronome relativo em "Este é lugar onde se guarda a carne." ou conjunção/ pronome relativo em "Não sei onde você está com a cabeça para fazer uma coisa dessas!". Se atentarmos para a constituição histórica, poderíamos classificar cadê como pronome, da classe dos interrogativos, já que contém um pronome que na forma fonte.

Para a questão do encaixamento das novas formas em paradigmas já existentes ou que passam a constituir novos paradigmas, sugerimos a leitura de Diewald (2008) e Diewald e Smirnova (2012). Estas últimas sugerem o acréscimo de um quarto estágio, o da integração paradigmática, aos três anteriormente apresentados: (i) pré-condições da gramaticalização; (ii) desencadeamento da gramaticalização; (iii) reorganização e diferenciação, visto que os novos itens gramaticalizados vão se integrar num (outro) paradigma, tendo em vista o novo significado que adquiriram no processo (DIEWALD; SMIRNOVA, 2012, p. 128).

A falta de segurança na classificação das novas formas que surgem na língua portuguesa (assim como em outras) deve-se ao fato de que as descrições de língua continuam a alicerçar-se na classificação milenar das partes do discurso ou classes gramaticais. Se elas já eram problemáticas na antiguidade - lembremos que o latim, que não tinha artigo, inseriu a classe das interjeições (que equivalem a frases!) para ficar com igual número de partes do discurso que a língua grega apresentava -, na atualidade estão mais comprometidas, haja vista a que, por processos como os de gramaticalização, novas formas são constituídas, como os MDs, que ainda não se sabe onde colocar ou que função sintática desempenham. Lembremos ainda dos dativos ético, de posse e de interesse que permanecem com denominação morfológica porque a sintaxe não dispõe de categoria gramatical para atribuir-lhes função sintática. 
Com respeito ao fato de se considerar as formas gramaticalizadas cadê, quedê, quede, quedele, cadele ou a mais recente cade quê como brasileirismos ou plebeísmos, creio que os fatos históricos e os dados, inclusive da língua literária, aqui aduzidos permitem desmentir tais rótulos, resultado da falta de conhecimento da história da língua, tanto do lado de cá como do lado de lá do Atlântico.

\section{Referências}

ARAUJO, L. de. Contos e historias. Lisboa: Typographia Universal, 1871.

ÁlVARES, A. Auto de Santo António. Pref., notas e glossário do Prof. Almeida Lucas. Lisboa: Edição da 'Revista de Portugal', 1948.

Auto de Dom André. Texto de autor anónimo quinhentista. Leit., apres., regul., notas e glossário por Maria José Palla. Lisboa: INCM, 1993.

Autos e comédias portuguesas por Antonio Prestes, Luis de Camões e outros autores portugueses. (Lisboa, 1587). Edição facsimilada. Pref. de Hernâni Cidade. Nota bibliog. José V. de Pina Martins. Lisboa: Lysia, 1973.

BACK, E.; MATTOS, G. Gramática construtural da língua portuguesa. São Paulo: FTD, 1972.

BUESCU, M. L. C. Monsanto: etnografia e linguagem. 2. ed. Lisboa: Presença, 1984 [1958].

CAMÕES, L. de. Auto chamado de Filodemo. In: Autos e comédias portuguesas por Antonio Prestes, Luis de Camões e outros autores portugueses. (Lisboa, 1587). Edição facsimilada. Pref. de Hernâni Cidade. Nota bibliog. José V. de Pina Martins. Lisboa: Lysia, 1973. f. 144r. a $162 \mathrm{v}$.

LISBOA, E. (Coord.) Dicionário cronológico de autores portugueses. Organizado pelo Instituto Português do Livro. Mem Martins: Publicações Europa-América, 1985. V. I.

DIEWALD, G. The catalytic function of constructional restrictions in grammaticalization. In: VERHOEVEN, E. et al. (eds). Studies on grammaticalization. Berlin/New York: Mouton de Gruyter, 2008. p. 219-239. 
DIEWALD, G.; SMIRNOVA, E. Paradigmatic integration: the fourth stage in an expanded grammaticalization scenario. In: DAVIDSE, K. et al. (eds). Grammaticalization and language change: new reflections. Amsterdam/Philadelphia: John Benjamins, 2012. p. 111-133.

FERREIRA, A. B. de H. Novo dicionário da língua portuguesa. 1. ed. 11. impr. Rio de Janeiro: Nova Fronteira, 1975.

FLORÊNCIO, M. Dialecto alentejano: contributos para o seu estudo. 2. ed. Lisboa: Colibri, 2005 [2001].

HEINE, B. et al. From cognition to grammar: evidence from African languages. In: TRAUGOTT, E.; HEINE, B. (eds.) Approaches to grammaticalization. Amsterdam/Philadelphia: John Benjamins, 1991. V. I: Focus on theoretical and methodological issues, p. 149-187.

HEINE, B.; CLAUDI, U. On the rise of grammatical categories. Some examples from Maa. Berlin: Dietrich Reimer, 1986.

HOPPER, P. J.; TRAUGOTT, E. C. Grammaticalization. Cambridge: CUP, 1993.

HOUAISS, A. Dicionário houaiss da língua portuguesa. Rio de Janeiro: Objetiva, 2001.

KURYLOWICZ, J. The evolution of grammatical categories. In:

Esquisses Linguistiques. München: Wilhelm Fink Verlag, 1975. V. II, p. 38-54.

LEITE, F. J. M. Grammatica portugueza dos lyceus: em que se contém toda a doutrina exigida pelo ultimo programma official, organisado pelo Conselho d'Instrucção Publica. Porto: Civilisação, 1887.

LEHMANN, C. Thoughts on grammaticalization: a programmatic sketch. Köln: Universität zu Köln, Institut für Sprachwissenschaft, 1982. (Arbeiten des Kölner Universalien-Projekts, 48). V. 1.

LI, C. N. Synchrony vs. diachrony in language structure. Language, Baltimore, v. 51, n. 4, p. 873-886, 1975.

LICHTENBERK, F. On the gradualness of grammaticalization. In: TRAUGOTT, E.; HEINE, B. (eds.) Approaches to grammaticalization. Amsterdam/Philadelphia: Benjamins. 1991. V. I: Focus on theoretical and methodological issues, p. 37-80.

MEILLET, A. L'évolution des formes grammaticales. In: MEILLET, A. Linguistique historique et linguistique générale. Réimpression de 
l'édition de Paris, 1975. Genève/Paris: Slatkine/Champion, 1982. p. 130-148.

MELLO MORAES FILHO. O Bumba-meu-boi. In: PADILHA, V. Os roceiros. Rio de Janeiro: Livraria do Povo, 1899. p. 183-191.

MENON, O. P. S. Vogais? chuá ... chuá ... João Pessoa, 2007. (Comunicação apresentada no I SIS Vogais, realizado na Universidade Federal da Paraíba, em João Pessoa, entre 15 a 17 de novembro de 2007).

MENON, O. P. S. Desde quando existe chuá em português? Valencia, 2010. (Comunicação apresentada no 26. ${ }^{e}$ SILFR: Congrés Internacional de Lingüística i Filologia Romàniques, realizado na Universitat de València, em Valência, entre 6 e 11 de setembro de 2010).

MENON, O. P. S. Cadê / Quedê você? Londrina, 2014. (Comunicação apresentada na mesa-redonda Morfologia do III CIDS: Congresso Internacional de Dialetologia e Sociolinguística, realizado na Universidade Estadual de Londrina, em Londrina, entre 7 e 10 de outubro de 2014).

PALMA-FERREIRA, J. Novelistas e contistas portugueses do século XVI. Pref., selecção e notas de João Palma-Ferreira. Lisboa: INCM, 1982.

SÁ DE MIRANDA, F. de. Obras completas. 3. ed. Texto fixado, notas e pref. pelo prof. M. Rodrigues Lapa. Lisboa: Sá da Costa, 1960. V. I.

SAID ALI, M. Gramática secundária e Gramática histórica da língua portuguêsa. Ed. rev. e atual. Brasília: Ed. da UnB, 1964.

TRAUGOTT, E.; HEINE, B. (eds.) Approaches to grammaticalization. Amsterdam/Philadelphia: Benjamins, 1991. V. I: Focus on theoretical and methodological issues.

TEATRO português do século XVI. Introd. e edição de José Camões. Lisboa: INCM, 2007. V. I, Teatro Profano, T. I.

TEATRO português do século XVI. Introd. e edição de José Camões. Lisboa: INCM, 2010. V. I, Teatro Profano, T. II.

VASCONCELLOS, J. F. de. Comédia Eufrosina. Conf. a impressão de 1561, publ. por ordem da Academia das Sciências de Lisboa. Ed. de Aubrey D. G. Bell. Lisboa: Imprensa Nacional, 1918. [1555]

VASCONCELOS, J. L. de. Esquisse d'une dialectologie portugaise. Lisboa/Paris: Aillaud \& Cia, 1901. 